factors: a cross-sectional study. The Journal of Rheumatology. 2015; 42 (4) 645-653. doi: 10.3899/jrheum.141018.

[2] Tam L.-S., Shang Q., Kun E. W., Lee K.-L., Yip M.-L., Li M., Li T.K., Zhu T.Y., Pui M.O., Li E.K., Yu C.-M. The effects of golimumab on subclinical atherosclerosis and arterial stiffness in ankylosing spondylitis - a randomized, placebo-controlled pilot trial. Rheumatology. 2014;53(6):1065-1074. doi:10.1093/rheumatology/ket469.

Disclosure of Interest: T. Aksenova Shareholder of: nothing to declare, Grant/research support from: nothing to declare, Consultant for: nothing to declare, Employee of: nothing to declare, Paid instructor for: nothing to declare, Speakers bureau: nothing to declare, N. Ivashhenko Shareholder of: nothing to declare, Grant/research support from: nothing to declare, Consultant for: nothing to declare, Employee of: nothing to declare, Paid instructor for: nothing to declare, Speakers bureau: nothing to declare, S. Tsarenok Shareholder of: nothing to declare, Grant/research support from: nothing to declare, Consultant for: nothing to declare, Employee of: nothing to declare, Paid instructor for: nothing to declare, Speakers bureau: nothing to declare, V. Gorbunov Shareholder of: nothing to declare, Grant/research support from: nothing to declare, Consultant for: nothing to declare, Employee of: nothing to declare, Paid instructor for: nothing to declare, Speakers bureau: nothing to declare, P. Gromov Shareholder of: nothing to declare, Grant/research support from: nothing to declare, Consultant for: nothing to declare, Employee of: nothing to declare, Paid instructor for: nothing to declare, Speakers bureau: nothing to declare

DOI: 10.1136/annrheumdis-2017-eular.2914

\section{Psoriatic arthritis}

\section{AB0737 AA AMYLOIDOSIS IN RHEUMATOID ARTHRITIS AND IN PSORIATIC ARTHRITIS - A POSTMORTEM CLINICOPATHOLOGIC STUDY OF 173 PATIENTS}

Á. Apáthy ${ }^{1}$, M. Bély ${ }^{2}$. ${ }^{1}$ Department of Rheumatology, St. Margaret Clinic Budapest; ${ }^{2}$ Department of Pathology, Hospital of the Order of the Brothers of Saint John of God, Budapest, Hungary

Background: Rheumatoid arthritis (RA) and psoriatic arthritis (PsA), like all chronic autoimmune arthritides, may be complicated by AA amyloidosis (AAa).

Objectives: The aim of this study was to determine the prevalence and extent of $\mathrm{AAa}$ in RA and PsA patients, furthermore appraise the extent of amyloid A deposits in various organs.

Methods: At the National Institute of Rheumatology 11860 patients died between 1968 and 1998; among them 161 patients with RA and 12 with PsA. All of them were autopsied. RA and PsA were diagnosed clinically according to the criteria of the ACR $[1,2]$.

Amyloid deposits on different tissue structures [arteriole, small artery, medium size artery, venule, small vein, medium size vein, interstitial collagen fiber, reticulin fiber (collagen IV), basal laminas, nerve, renal glomerulus] of 6 organs [heart, lungs, liver, kidney, skin and brain] were determined histologically.

The extent of amyloid A deposition was evaluated by semi-quantitative, visual estimation on a 0 to 3 plus scale, based on the number of involved tissue structures per light microscopic field [3]. ("0": no amyloid deposits, "1": Sporadic, minimal amyloid deposits on different tissue structures, "2": less than five, "3": five or more involved tissue structures per microscopic field at objective magnification of $\mathrm{x} 20$ )

The average prevalence and extent of amyloid A deposits of RA and PsA patients and the average prevalence and extent of amyloid A deposits in various organs were compared by Student (Welch) t-probe.

Results: The prevalence (in \%) and the average extent of amyloid A deposits (absolute value) in various organs of RA and PSA patients are summarized in Table 1.

\begin{tabular}{|c|c|c|c|c|c|c|}
\hline Organs & $\begin{array}{c}\mathrm{RA}-\mathrm{AAa} \\
\text { Prevalence in \% }\end{array}$ & $\begin{array}{c}\text { PsA-AAa } \\
\text { Prevalence in \% }\end{array}$ & $\mathrm{p}<$ & $\begin{array}{c}\text { RA-AAa } \\
\text { Average extent }\end{array}$ & $\begin{array}{c}\text { PsA-AAa } \\
\text { Average extent }\end{array}$ & $\mathrm{p}<$ \\
\hline Kidney & 48,49 & 68,18 & 0,0611 & 0,99 & 1,41 & 0,0706 \\
\hline Heart & 56,97 & 38,89 & 0,0651 & 0,97 & 0,67 & 0,1065 \\
\hline Liver & 29,17 & 38,89 & 0,3014 & 0,60 & 0,67 & 0,3945 \\
\hline Lung & 29,80 & 15,00 & 0,0852 & 0,44 & 0,13 & 0,0002 \\
\hline Skin & 10,83 & 50,00 & 0,0000 & 0,18 & 1,00 & 0,0027 \\
\hline Brain & 0,00 & 0,00 & - & 0,00 & 0,00 & - \\
\hline Average/Organ & 29,21 & 35,16 & 0,332 & 0,529 & 0,645 & 0,341 \\
\hline Average/Patient & 32,27 & 36,21 & 0,244 & 0,585 & 0,668 & 0,198 \\
\hline
\end{tabular}

Conclusions: Based on the nearly same 0,585 versus 0.668 , significantly not different: $p<0.198$ ) average amount of amyloid $A$ deposits/patient, the immune processes (producing amyloid A deposition) of our RA and PsA patients may be similar.

The more prominent amyloid deposition in the lungs of RA patients (in contrast with PsA patients) may be associated with more frequent and pronounced pulmonary complications of RA (vasculitis, interstitial pneumonitis and fibrosis, etc.), than by PsA.

Extreme severe amyloid deposition in the skin of PsA patients may be due to local factors, namely severe systemic dystrophic changes of the skin in psoriasis.
A diverse affinity of amyloid $A$ to qualitative changed collagens cannot be ruled out in PsA in comparison with RA. In systemic sclerosis patients such change of collagens has been demonstrated [4].

\section{References:}

[1] Arnett FC et al: Arthritis Rheum. 1988; 31(3):315-24. PMID: 3358796.

[2] Helliwell PS, Taylor WJ: Classification and diagnostic criteria for psoriatic arthritis. Ann Rheum Dis 2005;64:ii3-ii8 doi:10.1136/ard.2004.032318.

[3] Bély M, Apáthy Á: Clinical pathology of rheumatoid arthritis: Cause of death, lethal complications and associated diseases in rheumatoid arthritis. 1-440 pp. Akadémiai Kiadó, Budapest 2012.

[4] Istok R, Bély M, Stancikova M, Svik K, Rovensky J: Annals Rheum Dis 1999; 58(Suppl. 1):192.

Disclosure of Interest: None declared

DOI: 10.1136/annrheumdis-2017-eular.1224

\section{AB0738 PRECLINICAL IMPAIRMENT OF MYOCARDIAL FUNCTION AND ENDOTHELIAL VASCULAR MARKERS IN EARLY PSORIATIC ARTHRITIS: ASSOCIATION WITH VITAMIN D LEVELS AND INFLAMMATION}

A. Lo Gullo ${ }^{1}$, G. Mandraffino ${ }^{2}$, C.O. Aragona ${ }^{2}$, V. Cairo ${ }^{2}$, A. Saitta ${ }^{1} .{ }^{1}$ Clinical and Experimental Medicine; ${ }^{2}$ Policlinico G Martino, Messina, Italy

Background: Patients with psoriatic arthritis (PsA) have an increased prevalence of cardiovascular risk factors such as hypertension, myocardial dysfunction, and type 2 diabetes mellitus, and cardiovascular diseases (CVD) are the leading cause of death in these patients.

Furthermore, PsA patients have a high prevalence of vitamin D (vit-D) deficiency, considered an independent predictor of cardiovascular diseases and all-cause mortality in several clinical settings.

Objectives: We aimed to evaluate left ventricular (LV) mechanics in patients diagnosed with PsA and no clinical evidence for cardiovascular disease (CVD) using a more sensitive technique, which evaluates myocardial deformation in multidimensional planes for the detection of impaired LV function. Furthermore we evaluated carotid intima media thickness (cIMT) and pulse wave velocity (PWV), circulating proangiogenic haematopoietic cells (PHCs), as markers of endothelial dysfunction. We investigated the association between vitamin $D$ levels, inflammatory mediators, markers of endothelial and myocardial dysfunction in patients with PsA.

Methods: The study enrolled 19 PsA patients and 16 sex- -age matched healthy controls. All participants underwent conventional echocardiography and 2-dimensional speckle tracking echocardiography (STE). Global longitudinal, circumferential, and radial strain were measured. PHCs, Vitamin D levels, Creactive protein (CRP), fibrinogen, (PWV), (cIMT) were also evaluated.

Results: PHCs count and vitamin D levels were lower in PsA patients as compared to controls, while fibrinogen, CRP, PWV and cIMT were higher in PsA patients. STE analysis showed that PSA patients had significantly lower global longitudinal strain $(-16.11 \pm 2.89 \%$ and $-19.15 \pm 1.9 \%$, respectively, $p=0.05)$ and global circumferential strain $(-14.21 \pm 2.7 \%$ and $-20.22 \pm 4.13 \%$, respectively, $\mathrm{p}<0.01$ ) versus control group.

No correlation was found between longitudinal and circumferential strains and disease-related risk factors.

Vitamin D levels was found to correlate with longitudinal strain, ejection fraction, PHCs, diseases activity markers, and fibrinogen levels.

Conclusions: Subclinical impaired myocardial deformation and endothelial dysfunction were common in patients with PsA even when there is no clinical evidence for CVD. Furthermore, vitamin $D$ seems to may have a role in the endothelial homeostasis and myocardial function.

Further studies on larger sample sizes could clarify whether a supplementation of Vitamin D could modify PHCs levels inflammatory indices, myocardial function and arterial stiffness in patients affected by PsA, therefore contributing to reduce cardiovascular risk in this patients.

References:

[1] Gladman DD, Ang M, Su L, et al. Cardiovascular morbidity in psoriatic arthritis.Ann Rheum Dis 2009;68:1131-5.

[2] Han $\mathrm{C}$ et al. Cardiovascular disease and risk factors in patients with rheumatoid arthritis, psoriatic arthritis, and ankylosing spondylitis.J Rheumatol 2006;33:2167-72

[3] Lo Gullo A al. Vitamin D Status in Rheumatoid Arthritis: Inflammation, Arterial Stiffness and Circulating Progenitor Cell Number. PLoS One. 2015 Aug 4;10(8):e0134602.

[4] Assalin HB, Rafacho BP, dos Santos PP, et al. Impact of the length of vitamin D deficiency on cardiac remodeling. Circ Heart Fail. 2013;6:809-16.

Disclosure of Interest: None declared

DOI: 10.1136/annrheumdis-2017-eular.5189 